\title{
Examination of Bilateral and Unilateral Isokinetic Leg Strengths of Taekwondo Athletes and Boxers
}

\author{
Sevde Mavi $\operatorname{Var}^{1}$ \\ ${ }^{1}$ School of Physical Education and Sports, Ahi Evran University, Kirsehir, Turkey \\ Correspondence: Sevde Mavi Var, School of Physical Education and Sports, Ahi Evran University, Kirsehir, \\ Turkey. E-mail: sevde.mavivar@ahievran.edu.tr
}

\author{
Received: December 20, 2018 Accepted: January 18, 2019 Online Published: January 25, 2019 \\ doi:10.5539/jel.v8n1p272 URL: https://doi.org/10.5539/jel.v8n1p272
}

\begin{abstract}
The purpose of this research is to examine the maximal isokinetic leg strengths of male athletes who work in different branches of taekwondo and boxing, both bilateral and unilateral, as right and left legs. Totally 32 athletes, including taekwondo athletes $(n=16)$ and boxer $(n=16)$, participated in the study. In the 2016-2017 season, the average age of these athletes is $\bar{x}=21.5$. Biodex isokinetic system 4-Pro analyzing device was used in the study and $180^{\circ} / \mathrm{s}$ flexion and extension right and left leg maximal strength measurements were made from this measurement. Before the measurements, the athletes performed the exercise program including 15 minutes of warm-up movements and the maximal strength measurement was applied to each athlete 2 times. Their best performances were recorded and evaluated. When the findings of the study were examined, the right extension, right flexion, left extension, and left extension isokinetic strengths of the taekwondo athletes were found to be higher than the boxers. There was a very high and meaningful correlation found between right flexion and left flexion isokinetic strengths in the boxers between right extension and left extension isokinetic strengths. In Taekwondo athletes, there was a weak and meaningless correlation between right flexion and left flexion kinetic strengths and a positive correlation was found between right extension and left extension isokinetic strengths. Consequently, it was seen that isokinetic maximal leg strength of taekwondo athletes was higher than boxers. It is believed that this is due to the more intensive use of lower extremity muscles in taekwondo. Besides, in this research, there was a very high correlation between the right and left extension of the boxers and isokinetic leg strengths at the flexion while there was a weak meaningless correlation between the right flexion and left flexion isokinetic strengths of the taekwondo athletes, and a positive correlation was found between the right extension and the left extension isokinetic strengths. Thus, in the right and left isokinetic leg strength values of the boxers there was closeness, and in the right and left isokinetic strength values of them it can be said there was not so much closeness exists.
\end{abstract}

Keywords: isokinetic leg strength, bilateral, unilateral, taekwondo, boxing

\section{Introduction}

Taekwondo and boxing is an Olympic sports branch that appeal to a wide audience in many countries of the world. Although Taekwondo and boxing branches are common, which require challenging things they have common points such as the characteristics of being a martial sport they differ in terms of application and extremity in which they are used predominantly. Boxing sport is mostly applied with upper extremity muscles and taekwondo sport is applied with lower extremity muscles. The simplest and main reason for this is the practice of boxing with fist techniques, and the fact that taekwondo sport is a branch that is done with kicks.

Taekwondo means 'tae' kicking by using the foot, 'kwon' means kicking by using the hand or the fist and "do" means that it is related to art. In other words, the meaning of taekwondo is expressed as kick and fist art (Lee \& Kim, 2007). Taekwondo sport is divided into two branches as poomsea and kyorugi. Foot techniques are mostly used in the Olympic kyorugi branch (Atasoy et al., 2018). Therefore, it is known that the strength of the lower extremity muscles of the kyorugi branch of taekwondo is more crucial (Mavi Var, 2018).

Boxing is a branch which is mostly used in the branches that require body contact and struggle and the upper extremity is used predominantly (Çakmakçı, 2002). It is a sport where sudden combined strokes are present and energy loss is at the highest level. In this respect, maximal strength and anaerobic power are very important in 
boxing (Selçuk, 2014). Boxing has a complex structure consisting of high performance, dynamic and static features and is included in the branches of struggle that require strength and effort (Mitchell et al., 1999).

The isokinetic contraction refers to the continuation of the movement at an equal speed and the change of the resistance to the strength that the muscle will produce at that angle while the motion is performed at a constant speed. Such movements can be carried out in laboratory environments with very expensive and demanding tools such as isokinetic dynamometer (Günay et al., 2006). In the moment of isokinetic contraction, tension is maximally formed in the muscle along the entire angle of motion. When the muscle is shortened, the resistance to movement increases, the spasm in the muscle is permanent in the entire joint and the speed of the movement, however, the speed of the moment also 273emains stable (Robertson \& Glover, 1989). Biodex dynamometer is a device that (fixed by dynamometer) in the moment of isokinetic movement it examines the muscle strength and provides movement in a range of static and a specific angular speed (Newton \& Waddell, 1993). The isokinetic strength evaluation of leg extension and flexion and concentric prolonged spasms are important parts of the comprehensive evaluation of athletes (Gonzalez-Rave et al., 2014). Isokinetic strength measurements are extremely important in terms of preventing injury and increasing physical performance of athletes. With the isokinetic dynamometers used to determine the muscle balance and strength between the dominant/non-dominant and the agonist/antagonist, it helps coaches in the performance evaluation of athletes (Paasuke et al., 2001). When we look at the studies examining the right and left leg strengths, it is seen that the harmony between the legs is vague. It is because some studies report the presence of harmony between the right and left legs in athletes, while other studies reported that there is no fit (Jones \& Bampouras, 2010; Cheung et al., 2012).

In the light of this information, the aim of this study is to investigate the right and left leg isokinetic strengths of bilateral and unilateral taekwondo and boxing athletes. Taekwondo is mostly used in the lower extremity and boxing is a sports branch that uses the upper extremity. The main objectives of this study are to determine if these differences affect the isokinetic leg strength or not.

\section{Method}

\subsection{Study Group}

Totally 32 athletes participated in the study as 16 taekwondo athletes and 16 boxers. These athletes who participated in the contests in the 2016-2017 seasons are on the elite level. All athletes participated in the study voluntarily. The participants were cared for not to have an acute and chronic disability. The mean age of boxers was 21.12; the mean of taekwondo athletes was 22.12 ; the mean length of boxers was $180.25 \mathrm{~cm}$; the mean length of taekwondo athletes was $175.75 \mathrm{~cm}$; the mean weight of boxers was $78.50 \mathrm{~kg}$ and the mean weight of boxers was $66.25 \mathrm{~kg}$.

\subsection{Isokinetic Muscle Strength Measurement}

In the study, maximal strength measurement of $180^{\circ}$ s flexion and extension was performed in Biodex Isokinetic System 4-Pro analyzer, both right and left legs of the athletes bilateral and unilateral. More than 30 years have passed since Biodex introduced the world's first multi-mode computerized robotic dynamometer. The origin country of Biodex analyzer is United States of America (Biodex, 2018). Before the measurements, the athletes applied the exercise program including 15 minutes of warm-up movements and the maximal strength measurement was applied to each athlete 2 times. Their best performances were recorded and evaluated.

\subsection{Statistical Analysis}

For the analysis of the data acquired from this study, descriptive statistics (Table 1), Independent T test (Table 2) and Spearman Correlation (Table 3 and Table 4) performed by applying SPSS 22.0 package program for Windows. Since the number of athletes (32) was over 30, Kolmogorov-Smirnov table was considered. According to Kolmogorov-Smirnov table; since the variables are ( $>0.05)$, they were normally distributed. Therefore, parametric tests were applied to the variances.

\section{Results}

In this part, the findings of the statistical analysis of the data obtained from the research are presented. The descriptive statistics of the participants in the study (Table 1), comparison of the right and left leg flexion and extension isokinetic strengths (Table 2) of the boxing and taekwondo athletes, the pearson relationship of the right and left leg flexion and extension isokinetic strengths (Table 3), left and right of the taekwondo athletes the Pearson relationship of leg flexion and extension isokinetic strengths (Table 4) is given in the tables below. 
Table 1. Descriptive statistics of athletes

\begin{tabular}{lcc}
\hline Variables & $\begin{array}{c}\text { Boxing } \\
(\mathbf{n}=\mathbf{1 6}) \\
\mathbf{\mathbf { x }} \pm \mathbf{s d}\end{array}$ & $\begin{array}{c}\text { Taekwondo } \\
(\mathbf{n}=\mathbf{1 6}) \\
\overline{\mathbf{x}} \pm \mathbf{s d}\end{array}$ \\
\hline Age & $21.12 \pm .80$ & $22.12 \pm 2.21$ \\
\hline Length $(\mathrm{cm})$ & $180.25 \pm 8.85$ & $175.75 \pm .06$ \\
\hline Weight $(\mathrm{kg})$ & $78.50 \pm 11.19$ & $66.25 \pm 5.92$ \\
\hline Right extension & $137.68 \pm 33.65$ & $146.13 \pm 25.59$ \\
Right flexion & $111.63 \pm 31.49$ & $112.55 \pm 17.68$ \\
Left extension & $141.05 \pm 26.97$ & $146.82 \pm 28.11$ \\
Left flexion & $107.93 \pm 23.74$ & $108.33 \pm 14.55$ \\
\hline
\end{tabular}

Table 2. Comparison of right and left leg flexion and extension isokinetic strengths of boxer and taekwondo athletes

\begin{tabular}{|c|c|c|c|c|c|c|}
\hline Variables & Branch & $\mathbf{N}$ & $\overline{\mathbf{x}} \pm \mathbf{s d}$ & & t & $\mathbf{P}$ \\
\hline \multirow{2}{*}{ Right extension } & Boxing & 16 & 137.69 & 33.66 & \multirow{2}{*}{-.799} & \multirow{2}{*}{.430} \\
\hline & Taekwondo & 16 & 146.13 & 25.60 & & \\
\hline \multirow{2}{*}{ Right flexion } & Boxing & 16 & 111.63 & 31.49 & \multirow{2}{*}{-.101} & \multirow{2}{*}{.920} \\
\hline & Taekwondo & 16 & 112.55 & 17.69 & & \\
\hline \multirow{2}{*}{ Left extension } & Boxing & 16 & 141.05 & 26.98 & \multirow{2}{*}{-.593} & \multirow{2}{*}{.558} \\
\hline & Taekwondo & 16 & 146.82 & 28.11 & & \\
\hline \multirow{2}{*}{ Left flexion } & Boxing & 16 & 107.93 & 23.74 & \multirow{2}{*}{-.057} & \multirow{2}{*}{.955} \\
\hline & Taekwondo & 16 & 108.33 & 14.55 & & \\
\hline
\end{tabular}

$* * * \mathrm{p}<0.001$.

Table 3. Pearson relationship of right and left leg flexion and extension isokinetic strengths of boxers $(\mathrm{n}=16)$

\begin{tabular}{|c|c|c|c|c|c|c|c|}
\hline Variables & & $\begin{array}{l}\text { Right } \\
\text { extension }\end{array}$ & $\begin{array}{l}\text { Right } \\
\text { flexion }\end{array}$ & \multicolumn{3}{|c|}{ Left } & Length \\
\hline Right flexion & $\mathrm{r}$ & $.780^{* * *}$ & & & & & \\
\hline Left extension & $\mathrm{r}$ & $.906^{* * *}$ & $.581^{*}$ & & & & \\
\hline Left flexion & r & $.883^{* * * *}$ & $.945^{* * * *}$ & $.687^{* * *}$ & & & \\
\hline Age & $\mathrm{r}$ & .049 & -.202 & .022 & -.119 & & \\
\hline Length & $\mathrm{r}$ & -.277 & -.387 & $-.508^{*}$ & -.292 & .130 & \\
\hline Weight & $\mathrm{r}$ & .420 & .276 & .318 & .225 & .170 & .298 \\
\hline
\end{tabular}

r: Interpretation of Pearson (r) correlation coefficient; 0.00-0.25 very weak, 0.26-0.49 weak, 0.50-0.69 middle, 0.70-0.89 high, 0.90-1.00 very high.

Table 4. Pearson relationship of right and left leg flexion and extension isokinetic strengths of taekwondo athletes $(n=16)$

\begin{tabular}{|c|c|c|c|c|c|c|c|}
\hline Variables & & $\begin{array}{l}\text { Right } \\
\text { Extension }\end{array}$ & $\begin{array}{l}\text { Right } \\
\text { flexion }\end{array}$ & $\begin{array}{l}\text { Left } \\
\text { extension }\end{array}$ & $\begin{array}{l}\text { Left } \\
\text { flexion }\end{array}$ & Age & Length \\
\hline Right flexion & $\mathrm{r}$ & $.721^{* *}$ & & & & & \\
\hline Left extension & $\mathrm{r}$ & $.880^{* * *}$ & $.715^{* * *}$ & & & & \\
\hline Left flexion & $\mathrm{r}$ & $.510^{*}$ & .317 & $.603^{*}$ & & & \\
\hline Age & r & .029 & $-.536^{*}$ & -.081 & .138 & & \\
\hline Length & $\mathrm{r}$ & $.745^{* * *}$ & $.811^{* * * *}$ & $.800^{* * *}$ & .418 & -.073 & \\
\hline Weight & $\mathrm{r}$ & $.556^{*}$ & $.602^{*}$ & .479 & -.152 & -.134 & $.697^{* *}$ \\
\hline
\end{tabular}

r: Interpretation of Pearson (r) correlation coefficient; 0.00-0.25 very weak, $0.26-0.49$ weak, $0.50-0.69$ middle, $0.70-0.89$ high, $0.90-1.00$ very high.

\section{Discussion}

When the results of this study are examined, it can be seen that the right extension $(\overline{\mathrm{x}}=146.13)$, right flexion $(\overline{\mathrm{x}}=112.55)$, left extension ( $\overline{\mathrm{x}}=146.83)$, left flexion $(\overline{\mathrm{x}}=108.34)$, isokinetic strengths were found to be higher than boxers, but these results were statistically not significant. 
There was a very high positive correlation between right flexion and left flexion isokinetic strengths $(\mathrm{r}=.945, \mathrm{p}$ $<0.001)$ and right extension left extension isokinetic strengths of boxers $(r=.906, p<0.001)$. There was a positive meaningful correlation between right flexion and right extension $(r=.780, p<0.001)$ and left extension with left flexion $(\mathrm{r}=.687, \mathrm{p}<0.01)$.

In taekwondo athletes, there was a poor meaningless correlation between right flexion and left flexion isokinetic strengths $(\mathrm{r}=.317, \mathrm{p}>0.05)$. There was a positive and highly meaningful correlation found between right extension and left extension isokinetic strengths $(\mathrm{r}=.880, \mathrm{p}<0.001)$. A positive positive correlation was found between right flexion and right extension $(\mathrm{r}=.721, \mathrm{p}<0.01)$, and a meaningful average level positive correlation was found between left flexion and left extension $(\mathrm{r}=.603, \mathrm{p}<0.05)$.

In the study of Yapıcı et al. (2016), which is similar to this study, the effect of swimmers on the lower extremity isokinetic strength performance and swimming degrees was investigated. When the maximal isokinetic strength values of $180^{\circ} / \mathrm{s}$ right and left leg extension of swimmers divided into 3 groups; right $=1$. Group: 89.27, Group 2: 86.28 and Group 3: 125, left $=1$.group: 97, group 2: 87.14, group 3: 96.14 . When the maximal isokinetic strength values of $180^{\circ} / \mathrm{s}$ right and left leg flexion are examined it was seen that; right $=1$.group: 87.5 , 2nd group: 81.85 and 3rd group: 96.14 , left $=74.75,69.14,88.71$. In our study, the maximal isokinetic strength values of $180^{\circ} / \mathrm{s}$ right and left extremity flexion were found higher than the study of Yapic1 et al. (2016). This may be due to the fact that athletes in our study are branches where strength is more prominent, such as taekwondo and boxing.

In the research of Drouin et al. (2004) they evaluated the mechanical reliability and validity of position, torque and speed measurements of the Biodex System 3 isokinetic dynamometer quantitatively. At the end of the study, Biodex System 3 tests indicated acceptable mechanical reliability and validity for all tested variables, except for speeds of $300 \% \mathrm{~s}$ and higher

Alvares et al. (2015) report that evaluation of the reliability of Biodex System 3 Pro and Cybex Humac Norm Model 770 dynamometers for knee extensor and knee flexor strength measurements in isometric, concentric and eccentric tests, no statistically significant difference was found between Biodex and Cybex tests. Therefore, the maximum knee extensor and knee flexor tests performed on isometric, concentric and eccentric modes in Biodex and Cybex dynamometers showed similar values.

Tsiros et al. (2011) evaluated the Biodex System 4 isokinetic dynamometer critically for the evaluation of children. It was seen that the dynamometer had insufficient height adjustment for some children. It was very difficult to hold the non-test leg in the passive and eccentric mode and the leg bracket was retained for this. It was said that many of these obstacles were overcome and that the Biodex System 4 could be adapted to examine knee strength in children.

Özkan et al. (2009)'s research has been done in a similar method to our study. However, in our study, $180^{\circ} / \mathrm{s}$ isokinetic strength evaluation was performed and Özkan et al. (2009) evaluated the isokinetic strength at $150^{\circ} /$ scattering speed. The dominant isokinetic maximal $150^{\circ} / \mathrm{s}$ leg strength of the American football players the average was found as 129.758 in extension and the average is 94.64 in the flexion.

Bradic et al (2009)'s elite male basketball players in his research on $30 \% \mathrm{~s}, 60 \% \mathrm{~s}$ and $180 \% \mathrm{~s}$ maximal isokinetic knee and ankle extension and flexion strengths were examined. The results showed that the ankles had significantly stronger plantar flexors and dorsal flexors at both angular speeds. This research is similar to the findings of our research and supports our research.

Similarly to our study, Potteiger et al. (2010), a study conducted on subelite male athletes, examined the relationship of 21 male ice hockey players with different variables of isokinetic leg strengths. In accordance with the results of Isokinetic and Wingate anaerobic strength test to be successful in male ice-hockey the power and accumulating of power skill is a vital thing.

Iga et al. (2009) examined the right and left isokinetic leg strength of the players. When the results were examined, it was seen that there were differences in the isokinetic strengths of right and left legs in young football players. It has been said that it can be enhanced by incorporating resistance training into customary exercise routines to eliminate these imbalances. In our study, it is seen that there are differences in the right and left leg isokinetic strengths of the athletes.

González-Ravé et al. (2014) examined the strength and strength of isokinetic leg in elite handball players. When the results were examined, it was observed that the differences between the legs were not significant in isokinetic knee extension. The results of this research also support our research results. 
In the research of Daneshjoo et al. (2013), asymmetric strength and resilience due to bilateral and unilateral isometric strength were examined in male young professional football players. Biodex Isokinetic Dynamometer was used to assess hamstring and quadriceps strength at $60^{\circ} / \mathrm{s}, 180^{\circ} / \mathrm{s}$ and $300^{\circ} / \mathrm{s}$. At all angular speeds, peak torques in the non-dominant leg were higher than the dominant leg, but these results were not found statistically meaningful similar to our study.

To sum up, it was seen that isokinetic maximal leg strength of taekwondo athletes was higher than boxers. It is thought that this is because of more intensive use of lower extremity muscles in taekwondo. Besides, the right and left isokinetic leg strength values of the boxers, there is closeness to the right and left isokinetic strength values of taekwondo athletes can be said there is not much closeness. In order to achieve high performance in sports, it is important for athletes to be equal to each other very close to each other in both right and left legs. Thus, from the beginning of preparation period athletes must train with planned and scheduled works in order to provide equal development of the strength of both legs.

\section{References}

Alvares, J. B. D. A. R., Rodrigues, R., De Azevedo Franke, R., Da Silva, B. G. C., Pinto, R. S., Vaz, M. A., \& Baroni, B. M. (2015). Inter-machine reliability of the Biodex and Cybex isokinetic dynamometers for knee flexor/ extensor isometric, concentric and eccentric tests. Physical Therapy in Sport, 16(1), 59-65. https://doi.org/10.1016/j.ptsp.2014.04.004

Atasoy, M., Karabulut, E. O., \& Var, L. (2018). The Research on The Negative Evaluation Anxiety of Taekwondo Players By Different Variables. Turkish Journal of Sport and Exercise, 20(3), 158-162. https://doi.org/10.15314/tsed.466880

Biodex. (2018). Biodex $\quad$ System 4 Pro. Retrieved from http://www.biodex.com/physical-medicine/products/dynamometers/system-4-pro

Bradic, A., Bradic, J., Pasalic, E., \& Markovic, G. (2009). Isokinetic leg strength profile of elite male basketball players. The Journal of Strength \& Conditioning Research, 23(4), 1332-1337. https://doi.org/10.1519/JSC.0b013e3181a0227e

Cheung, R. T., Smith, A. W., \& Wong, D. (2012). H:q ratios and bilateral leg strength in college field and court sports players. J Hum Kinet, 33(1), 63-71. https://doi.org/10.2478/v10078-012-0045-1

Çakmakç1, O. (2002). Selected Turkey and Georgia to compare the physical properties of the National Boxing Team. PhD thesis, Selçuk University Institute of Health Sciences.

Daneshjoo, A., Rahnama, N., Mokhtar, A. H., \& Yusof, A. (2013). Bilateral and unilateral asymmetries of isokinetic strength and flexibility in male young professional soccer players. Journal of Human Kinetics, 36(1), 45-53. https://doi.org/10.2478/hukin-2013-0005

Drouin, J. M., Valovich-McLeod, T. C., Shultz, S. J., Gansneder, B. M., \& Perrin, D. H. (2004). Reliability and Validity of the Biodex system 3 pro isokinetic dynamometer velocity, torque and position measurements. European Journal of Applied Physiology, 91(1), 22-29. https://doi.org/10.1007/s00421-003-0933-0

González-Ravé, J. M., Juárez, D., Rubio-Arias, J. A., Clemente-Suarez, V. J., Martinez-Valencia, M. A., \& Abian-Vicen, J. (2014). Isokinetic leg strength and power in elite handball players. Journal of Human Kinetics, 41(1), 227-233. https://doi.org/10.2478/hukin-2014-0050

Günay, M., Tamer, K., \& Cicioğlu, İ. (2006). Sport Physiology and Performance Measurement. Gazi Bookstore. Ankara.

Iga, J., George, K., Lees, A., \& Reilly, T. (2009). Cross- sectional investigation of indices of isokinetic leg strength in youth soccer players and untrained individuals. Scandinavian Journal of Medicine \& Science in Sports, 19(5), 714-719. https://doi.org/10.1111/j.1600-0838.2008.00822.x

Jones, P. A., \& Bampouras, T. M. (2010). A comparison of isokinetic and functional methods of assessing bilateral strength imbalance. $J$ Strength Cond Res, 24(6), 1553-1558. https://doi.org/10.1519/JSC.0b013e3181dc4392

Lee, M. G., \& Kim, Y. G. (2007). Effects of short-termweight loss on physical fitness, isokinetic leg strength, and blood variables in male high school taekwondo players. The 1st International Symposium for Taekwondo Studies, 2007 May 16-17; Beijing, China. 47-57.

Mavi Var, S. (2018). The Physical and Motoric Features in Taekwondo, I $\breve{g} d ı$ Üniversitesi Spor Bilimleri Dergisi, 1(1), 1-15. Retrieved from http://dergipark.gov.tr/igdirsbd 
Mitchell, H., Willams, L., \& Reter, B. R. (1999). Classification of sports medicine and science in sports and exercise. American College of Sports Medicine and the American College of Cardiology, 56-85.

Newton, M., \& Waddell, G. (1993). Trunk strength testing with iso-machines. Part 1: review of a decade of scientific evidence. Spine, 18(7), 801-811. https://doi.org/10.1097/00007632-199306000-00001

Özkan, A., Arıburun, B., \& Kin-İşler, A. (2009) .Relationships of Body Composition, Isokinetic Knee Strength and Anaerobic Performance in American Football Players. Turkiye Klinikleri Journal of Sports Sciences, $1(1), 47-52$.

Paasuke, M., Ereline, J., \& Gapeyeva, H. (2001). Knee Extension Strength And Vertical Jumping Performance In Nordic Combined Athletes. J Sports Med Phys Fitness, 41(3), 354-361.

Potteiger, J. A., Smith, D. L., Maier, M. L., \& Foster, T. S. (2010). Relationship between body composition, leg strength, anaerobic power, and on-ice skating performance in division I men's hockey athletes. The Journal of Strength \& Conditioning Research, 24(7), 1755-1762. https://doi.org/10.1519/JSC.0b013e3181e06cfb

Robertson, T., \& Glover, S. (1989). Senior Physical Education, Coghill Publishing. Australia.

Selçuk, M. S. (2014). The effect of 6-week resistance tire application on female maximal force and anaerobic power in female boxers. $\mathrm{PhD}$ Thesis, Selcuk University Institute of Health Sciences.

Tsiros, M. D., Grimshaw, P. N., Shield, A. J., \& Buckley, J. D. (2011). The Biodex isokinetic dynamometer for knee strength assessment in children: advantages and limitations. Work, 39(2), 161-167.

Yapıc1, A., Maden, B., \& Findıkoğlu, G. (2016). The effect of a 6-week land and resistance training of 13-16 years old swimmers groups to lower limb isokinetic strength values and to swimming performance. Journal of Human Sciences, 13(3), 5269-5281. https://doi.org/10.14687/jhs.v13i3.4158

\section{Copyrights}

Copyright for this article is retained by the author, with first publication rights granted to the journal.

This is an open-access article distributed under the terms and conditions of the Creative Commons Attribution license (http://creativecommons.org/licenses/by/4.0/). 